\title{
Focal Acral Hyperkeratosis with Intracorneal Retention of Keratohyalin Granules
}

\author{
Y Charli-Joseph*, RA García-Galaviz, J Domínguez-Cherit \\ Department of Dermatology, Instituto Nacional de Ciencias Médicas y Nutrición Salvador Zubirán, Mexico \\ *Corresponding Author: Y Charli-Joseph, Dermatology Department. Instituto Nacional de Ciencias \\ Médicas y Nutrición Salvador Zubirán, Mexico. Email: yanncj@gmail.com
}

\begin{abstract}
Acrokeratoelastoidosis (AKE) and focal acral hyperkeratosis (FAH) are rare genodermatoses with many shared clinical and histopathologically features, distinguished solely by the absence of elastorrhexis in FAH. We present a case of FAH in a 42-year-old woman with HIV-HVB co-infection that showed multiple skin-colored papules with central umbilication on the sides and dorsum of both hands and feet, without nail involvement. Histology showed compact hyperkeratosis with retention of intracytoplasmic basophilic keratohyalin granules and no dermal elastorrhexis. Retention of keratohyalin granules could relate to a primary defect of cornification in patients with FAH and, if reproducible, could potentially serve as a histopathological discriminator from AKE.
\end{abstract}

Keywords: Focal acral hyperkeratosis, Keratohyalin granules, Acrokeratoelastoidosis.

\section{INTRODUCTION}

Acrokeratoelastoidosis (AKE) and focal acral hyperkeratosis $(\mathrm{FAH})$ are rare genodermatoses with many shared clinical and histopathologic features, distinguished solely by the absence of elastorrhexis in FAH.1, 2, 3 FAH most frequently develops in childhood or early adult life, and is believed to display an autosomic dominant inheritance pattern with incomplete penetrance. Whilst it was initially reported to occur exclusively in females of African or Arabian descent, subsequent reports in males and Caucasians have refuted the importance of sex and race as distinctive diagnostic criteria.4, 5 , 6 Herein we portray a case of FAH in an HIV-infected patient and describe a histopathological finding previously unreported in the context of this pathology.

\section{CASE REPORT}

A 42-year-old Nigerian woman was referred to our outpatient clinic because of a papular rash on her hands and feet which began around puberty. Her mother and one niece reportedly displayed identical lesions. Our patient had been diagnosed with HIV-HVB co-infection 13 years earlier; her viral load was $<40$ and her CD4 count was 117 at the moment of the dermatological consultation, and was under HAART with efavirenz, emtricitabine and tenofovir. On physical examination multiple skin-colored papules with central umbilication were noted on the sides and dorsum of both hands and feet, without nail involvement (Figure 1). She regularly shaved such lesions and reported no associated symptoms, history of consanguinity nor arsenic exposure.

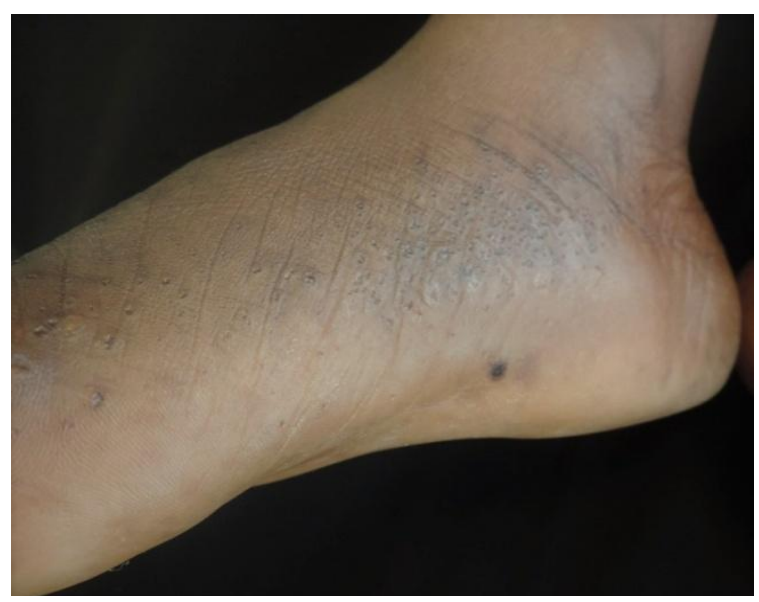

Figure1. Left foot's lateral aspect showing multiple skin-colored papules with central umbilication

\section{RESULTS AND DISCUSSION}

Histopathological analysis showed a sharply demarcated area of compact hyperkeratosis overlying a slightly depressed acanthotic epidermis with hypergranulosis, and no dermal elastorrhexis upon assessment with an elastic tissue stain. Upon higher power magnification it 
was noted that numerous corneocytes retained intracytoplasmic basophilic keratohyalin granules, conferring the affected stratum corneum a patchy bluish appearance (Figure 2).

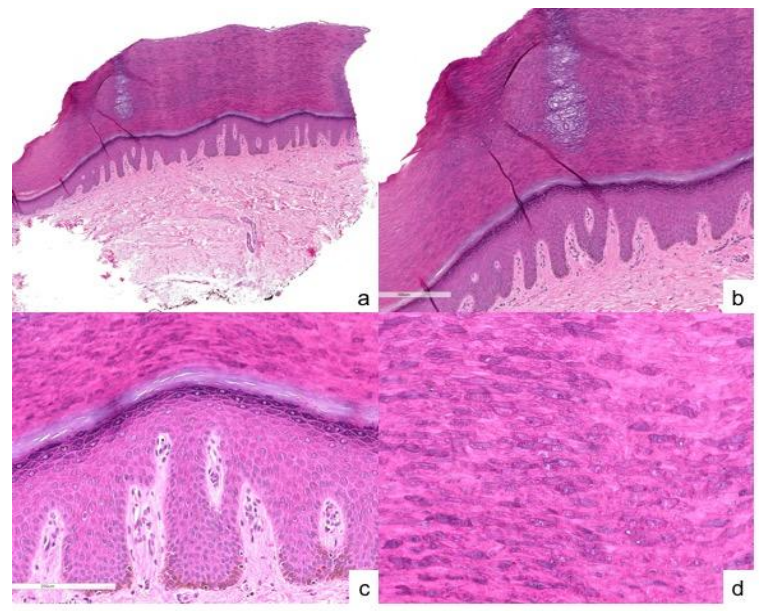

Figure2. Hematoxilin \& eosin: a) 20x, b) 40x, c) 200x, d) 400x. Sharply demarcated compact hyperkeratosis overlying a slightly depressed acanthotic epidermis with hypergranulosis. Retention of intracytoplasmic keratohyalin granules in the stratum corneum is evident upon higher magnification.

\section{Conclusion}

FAH is a benign condition that may cause cosmetic and psychological concern. Whilst it is easily distinguished from most acquired forms of papular acral dermatoses (verruca, digital calcinosis, acral mucinosis, etc) its histopathology is poorly specific and reportedly identical to AKE, except for the presence of elastorrhexis in the latter. This case is depicted due to the conspicuous retention of keratohyalin granules in the affected stratum corneum, akin to that described in cases of granular parakeratosis (GP), but without the presence of intracorneal nuclei (parakeratosis) or axillary /intertriginous lesions, characteristic of GP. ${ }^{[7]} \mathrm{To}$ our knowledge retention of keratohyalin granules had never been describe- ed in FAH and could merely represent a reaction pattern to external irritation (shaving) as suggested by others for GP. ${ }^{[8]}$ Alternatively, retention of keratohyalin granules could relate to a primary defect of cornification in patients with FAH and if reproducible could potentially serve as a histopathological discriminator from AKE.

\section{REFERENCES}

[1] Erkek E, Koçak M, Bozdogan Ö, Atasoy P, Birol A. Focal Acral Hyperkeratosis: A Rare Cutaneous Disorder within the Spectrum of Costa Acrokeratoelastoidosis. Pediatric Dermatology 2004; 21(2); 128-130.

[2] Van Steensel M, Frank J. Focal acral hyperkeratosis and acrokeratoelastoidosis: birds of a feather? J Eur Acad Dermatol Venereol 2009;23:1092-11

[3] Álvarez-Fernández JG, Gómez-De La Fuente E, Rodríguez-Vázquez M, Vicente-Martín FJ, Pinedo-Moraleda F, López-Estebaranz JL. Hiperqueratosis focal acral. Actas Dermosifiliogr 2002; 93(10):581-3

[4] Pereira-Marques L, Moritz-Trope B, Carnevale-Pina J, Cuzzi T, Ramos-e-Silva M. Inverse Papular Acrokeratosis of Oswaldo Costa: A Case Report. J Clin Aesthetic Dermatol. 2010;3(6):51-53

[5] Koudoukpo C, Bourrat E, Rausky J et al. Aïnhum et «kératodermies acrales africaines»: trois cas. Ann Dermatol Venereol 2015; 142(3):170-175

[6] Rivera R, Guerra A, Rodríguez-Peralto JL, Iglesias L. Acroqueratoelastoidosis: presentación de dos nuevos casos. Actas Dermosifiliogr 2003;94(4):247-50

[7] Ding CY, Liu H, Khachemoune A. Granular parakeratosis: A comprehensive review and a critical reappraisal. Am J Clin Dermatol 2015; 16(6):495-500

[8] Mehregan DA, Thomas JE, Mehregan DR. Intertriginous granular parakeratosis. $J \mathrm{Am}$ Acad Dermatol 1998; 39(3):495-496.

Citation: Y Charli-Joseph, RA García-Galaviz, J Domínguez-Cherit. Focal Acral Hyperkeratosis with Intracorneal Retention of Keratohyalin Granules ARC Journal of Dermatology. 2017; 2(1):22-23. doi:dx.doi.org/10.20431/2456-0022.0201005.

Copyright: (C) 2017 Authors. This is an open-access article distributed under the terms of the Creative Commons Attribution License, which permits unrestricted use, distribution, and reproduction in any medium, provided the original author and source are credited. 